\title{
EL SISTEMA DE PROTECCIÓN DEL PATRIMONIO HISTÓRICO URBANO Y MINERO EN BRASIL
}

\section{The Protection SCheme of the URban AND Mining Historical Heritage in BRAZIL}

\author{
EMERSON GABARDO \\ Professor de Direito Administrativo \\ Universidade Federal do Paraná \\ e.gab@uol.com.br \\ ENEIDA DESIREE SALGADO \\ Professora de Direito Constitucional \\ Universidade Federal do Paraná \\ e.gab@uol.com.br
}

Recibido: 5 de marzo de 2018 / Aceptado: 28 de mayo de 2018

RESUMEN: Este artículo tiene como objetivo presentar, desde un punto de vista histórico y legal, una descripción de la protección jurídica del patrimonio históricocultural urbano y minero en el derecho brasileño. Tras exponer la evolución histórica de dicha protección en Brasil, el estudio presenta las cuestiones conceptuales relativas a la tutela del patrimonio cultural, para después explicar el instituto urbanístico del tombamento en el sistema jurídico brasileño. Finalmente, el texto muestra las carencias de la protección del patrimonio minero en Brasil y los pasos ya adoptados en la realidad nacional para implementarla.

ABSTRACT: This paper has the objective of presenting a description, under the historical and legal points of view, about the legal protection of the historical-cultural urban and mining heritage in Brazilian Law. After explaining the historical evolution of this protection in Brazil, the study presents the conceptual issues related to the protection of cultural heritage, to then explain the urban development institute of the "tombamento" in the Brazilian legal system. Finally, the text indicates the lack of protection of the 
mining heritage in Brazil and the steps already taken in the national reality to implement it.

RESUM: Aquest article té com a objectiu presentar una descripció, des d'un punt de vista històric i legal, de la protecció jurídica del patrimoni històric-cultural urbà i miner en el Dret brasiler. Després d'explicar l'evolució històrica d'aquesta protecció al Brasil, l'estudi presenta les qüestions conceptuals relatives a la tutela del patrimoni cultural, per explicar posteriorment l'institut urbanístic del "tombamento" en el sistema jurídic brasiler. Finalment, el text indica la insipiència de la protecció del patrimoni miner al Brasil i els passos ja adoptats en la realitat nacional per implementar-la.

PALABRAS CLAVE: patrimonio histórico - tombamento - patrimonio minero patrimonio urbano - derecho brasileño.

KEYWORDS: historical heritage — tombamento — mining heritage — urban heritage Brazilian law.

PARAULES CLAU: patrimoni històric — tombamento — patrimoni miner — patrimoni urbà - Dret brasiler.

SUMARIO: I. Introducción. II. Evolución de la protección del patrimonio histórico en brasil. III. Cuestiones conceptuales relativas a la protección del patrimonio cultural. IV. La protección jurídica de los bienes culturales por medio del instituto urbanístico del tombamento. V. La debilidad respecto a la protección del patrimonio minero en brasil. VI. Conclusiones. VII. Referencias.

\section{INTRODUCCIÓN}

El artículo 216 de la actual Constitución brasileña garantiza la protección de los bienes históricos y culturales en su más amplia forma - como integrantes de un sistema ambiental material e inmaterial- Asimismo, trata expresamente de la importancia de la preservación de la memoria del pueblo y su "identidad colectiva". Asimismo, al mismo tiempo que la Constitución establece la protección de la "identidad colectiva", también exige que todas las políticas públicas consideren la "diversidad" cultural. Así, el ordenamiento jurídico brasileño adopta un concepto plural y abierto de patrimonio a ser 
preservado. La identidad no debe ser un concepto cerrado y estático, sino una idea dinámica, o sea, en constante construcción ${ }^{1}$.

En su primer párrafo, el artículo 216 establece que el poder público es responsable de la protección del patrimonio cultural $^{2}$, si bien prevé que esta debe realizarse con la colaboración de la comunidad ${ }^{3}$. Algunos instrumentos de actuación directa ya están descritos en la propia Constitución: inventarios, registros, vigilancia, tombamento y expropiación forzosa. Para la protección de los bienes culturales, sin duda, la forma más utilizada es el tombamento (cuyo concepto específico se explicará más adelante).

En Brasil, el patrimonio cultural es tanto el conjunto de bienes tangibles (sean muebles, como objetos de arte o litúrgicos, libros, documentos, joyas, máquinas o equipamientos; o inmuebles, como monumentos, núcleos urbanos, parques ecológicos, edificios, yacimientos arqueológicos, ambientes y paisajes urbanos y rurales) como el conjunto de bienes intangibles (ideas, costumbres, creencias, tradiciones orales, danzas, rituales, saberes y prácticas $)^{4}$.

Es importante subrayar qué parcela significativa de la doctrina brasileña considera que existe un "derecho fundamental al patrimonio cultural", que puede ser invocado por los ciudadanos ante los poderes públicos nacionales ${ }^{5}$. Este derecho fundamental comprende el cumplimiento de tres principios éticos relativos a la protección del patrimonio histórico y paisajístico: a) el principio de la conservación de opciones, o sea, debe asegurarse a las generaciones futuras un abanico de posibilidades de solución de sus problemas que

\footnotetext{
${ }^{1}$ RODRIGUES, Francisco Luciano Lima, Patrimônio cultural: a propriedade dos bens culturais no Estado Democrático de Direito, Universidad de Fortaleza, Fortaleza, 2008, p. 120.

2 Artículo 216: "Constituem patrimônio cultural brasileiro os bens de natureza material e imaterial, tombados individualmente ou em conjunto, portadores de referência à identidade, à ação, à memória dos diferentes grupos formadores da sociedade brasileira, nos quais se incluem: I - as formas de expressão; II - os modos de criar, fazer e viver; III - as criações científicas, artísticas e tecnológicas; IV - as obras, objetos, documentos, edificações e demais espaços destinados às manifestações artístico-culturais; V - os conjuntos urbanos e sítios de valor histórico, paisagístico, artístico, arqueológico, paleontológico, ecológico e científico".

${ }^{3}$ Artículo 216, párrafo 1. : “'O poder público, com a colaboração da comunidade, promoverá e protegerá o patrimônio cultural brasileiro, por meio de inventários, registros, vigilância, tombamento e desapropriação, e de outras formas de acautelamento e preservação".

${ }^{4}$ PELEGRINI, Sandra C., Patrimônio cultural: consciência e preservação, Brasiliense, São Paulo, 2009, p. 28.

${ }^{5}$ RODRIGUES, Patrimônio cultural... cit., p. 152.
} 
conserve la diversidad del patrimonio cultural y natural ambiental; b) el principio de la calidad, es decir, la generación presente debe transmitir a las generaciones futuras un patrimonio cultural de igual calidad al que posee - lo que remite a la idea de sostenibilidad-; y c) el principio de la conservación del acceso, según el cual debe asegurarse la igualdad de acceso a los bienes culturales entre los diferentes sujetos de derecho existentes ${ }^{6}$.

Desde la perspectiva de la Constitución brasileña, las políticas culturales deben superar el modelo liberal. La mera enunciación de principios y derechos por medio de los discursos produce desde luego un importante cambio social ${ }^{7}$. Aunque Estados como el brasileño fracasen sistemáticamente en la protección cultural y en la ambiental (debido sobre todo a las exiguas inversiones tanto en infraestructuras como en personal), la fuerza simbólica de la protección constitucional y legal transforma las relaciones históricas de subordinación y exclusión en relaciones de igualdad y lucha, aunque en medio de antagonismos y conflictos.

A pesar de que los mecanismos de protección del patrimonio histórico, cultural y ambiental brasileño todavía sean insatisfactorios, efectivamente importantes iniciativas — principalmente en los ámbitos académico y universitario-. Este artículo científico tiene el objetivo de explicar de forma descriptiva algunas de estas iniciativas, así como el conjunto de normas, institutos jurídicos y conceptos que se utilizan en Brasil para garantizar el cumplimiento de los principios de protección en términos jurídicos y técnicos.

\section{EVOLUCIÓN DE LA PROTECCIÓN DEL PATRIMONIO HISTÓRICO EN BRASIL}

La preservación del patrimonio nacional brasileño solo tiene inicio después de la instauración del Estado republicano, que tuvo lugar en $1889^{8}$. Los primeros órganos de protección del patrimonio histórico en Brasil fueron creados en la década de 1920: la

\footnotetext{
${ }^{6}$ SILVA, Fernando Fernandes da, As cidades brasileiras e o patrimônio cultural da humanidade, Editora da USP, São Paulo, 2012, 2. ${ }^{\text {e }}$ d., p. 39.

${ }^{7}$ FONSECA, O patrimônio... cit., p. 45.

${ }^{8}$ CAMARGO, Haroldo Leitão, Patrimônio Histórico e Cultural, Aleph, São Paulo, 2002, p. 19.
} 
Inspectoría Estatal de Monumentos de Minas Gerais (1926), la Inspectoría Estatal de Monumentos de Bahía (1927) y la Inspectoría Estatal de Monumentos de Pernambuco (1928) $)^{9}$. La Constitución de 1934 es la primera que estableció la protección de bienes de carácter histórico, natural o artístico típicos del ambiente urbano (en su texto, la palabra patrimonio no estaba presente todavía).

En 1936 fue instituido el Instituto del Patrimonio Histórico y Artístico Nacional (IPHAN). El IPHAN creó la Revista do Patrimônio con el propósito de difundir sus ideas en el ámbito intelectual ${ }^{10}$. Luego, el patrimonio material brasileño pasó a ser protegido legalmente a nivel nacional en 1937 por medio del Decreto-Ley 25. La protección de los denominados "bienes inmateriales", por su parte, es mucho más reciente. A pesar de estar prevista en la Constitución desde 1988, esta forma de protección fue reglamentada en el año 2000 mediante el Decreto 3.551. Y en 2004 se organizó el Departamento del Patrimonio Inmaterial (a nivel federal). Así, la historia brasileña en materia de protección del patrimonio histórico es mucho más tardía y tímida que la de otros Estados latinoamericanos. En este sentido, se puede aludir a una de las legislaciones más antiguas de las Américas, la mexicana, que ya poseía alguna especie de protección de bienes inmateriales en el artículo 4 de la Ley de 1930, además de haber aprobado varias leyes de protección a lo largo de su historia, comenzando por la Ley sobre monumentos arqueológicos de $1897^{11}$.

Actualmente, la mayoría de las antiguas inspectorías han sido transformadas en entes estatales dotados de autonomía, tales como el Instituto Estatal del Patrimonio Histórico y Artístico de Minas Gerais (IEPHA), que es una fundación pública creada en 1971 y, por lo tanto, tiene personalidad jurídica propia ${ }^{12}$.

\footnotetext{
${ }^{9}$ SOUZA, Luciana Christina Cruz y MORAES, Nilson Alves, "Estado e patrimônio: o IEPHA/MG e o caso de Minas Gerais“, IV Seminário Internacional - Políticas Culturais, Fundação Casa Rui Barbosa, Río de Janeiro, octubre 2013. Recuperado el 8 de enero de 2018 de $<$ http://culturadigital.br/politicaculturalcasaderuibarbosa/files/2013/11/Luciana-Christina-Cruz-e-Souzaet-alii.pdf.>.

${ }^{10}$ IPHAN - Instituto de Patrimonio Histórico y Artístico Nacional. Revistas e Boletins. Recuperado el 9 de enero de 2018 de <http://docvirt.com/docreader.net/DocReader.aspx?bib=G:|Trbs_NIRevIPHAN|RevIPHAN.docpro>.

${ }^{11}$ LEITE, Letícia Rosa de Almeida, "Patrimônio histórico no México (1914-1939): como surgem as leis e se selecionam memórias", XXVIII Simpósio Nacional de História, Florianópolis, 2015.

${ }^{12}$ SCHIRM, Letícia Dias, "Tombamento: multidisciplinaridade na preservação do patrimônio cultural", Simpósio Nacional de História, 2007, São Leopoldo, RS, Anais do XXIV Simpósio Nacional de História História e multidisciplinaridade: territórios e deslocamento, Unisinos, São Leopoldo, 2007. CD-ROM.
} 
Brasil inició su proceso de preservación patrimonial gracias a la influencia del movimiento modernista de São Paulo y Minas Gerais, que tuvo lugar en las décadas de 1920 y 1930, y que mezclaba sentimientos contradictorios, ora nacionalistas, ora internacionalistas ${ }^{13}$. Inicialmente había una grande preocupación por el barroco típico del período colonial brasileño (de 1500 a 1822). Una fuerte inspiración en el modelo europeo de protección de monumentos y valorización estética estaba presente en la búsqueda de un camino propiamente brasileño de regulación estética y jurídica de la materia.

La preocupación de la época por la cuestión jurídica inherente a la protección del patrimonio histórico urbano se situó en el centro del escenario general del asunto. El concepto de propiedad existente era muy limitado: diversos proyectos legislativos de protección del patrimonio fueron rechazados en el Parlamento por la radical protección de la propiedad privada a la sazón predominante. El reto del Gobierno de entonces era crear nuevos institutos de intervención del Estado en la propiedad, teniendo especialmente en cuenta la preservación de bienes históricos ${ }^{14}$.

Solo a partir de la década de 1940 los objetos entonces vistos como "trastos viejos" pasaron a ser considerados como valiosos. Paulatinamente se rechazó la visión "triunfalista" de la historia nacional (concentrada en los grandes momentos). La nueva historiografía pasó a refrendar una visión del patrimonio histórico como medio de recuperación de aspectos civilizatorios (lo que conllevó la preservación de todo a partir de su relación con la vida, con el medio ambiente y sus procesos cotidianos).

En ese momento, la cuestión de la actividad minera pasa a ser algo importante por su impacto histórico y ambiental. Por otro lado, continúa siendo prácticamente nulo el interés por el universo de la civilización indígena, que siempre ha estado íntimamente conectado con la actividad minera en Brasil. En todo caso, a pesar del reconocimiento de la relevancia de la actividad minera, la principal preocupación respecto a esta cuestión a partir de la década de 1940 no se dirigió a la protección de las máquinas y los equipamientos ligados a la minería. El objetivo eran los bienes relacionados con la arquitectura religiosa — esta sí, considerada de excepcional valor-. Solo a partir de las décadas de 1970 y 1980 se adopta una nueva postura, con el avance de una historia

\footnotetext{
${ }^{13}$ AMARAL, Aracy, "O modernismo brasileiro e o contexto cultural dos anos 20", Revista USP, núm. 94, junio/agosto 2012, São Paulo, pp. 9-18.

${ }^{14}$ FONSECA, Maria Cecília Londres, O patrimônio em processo: trajetória da política federal de preservação no Brasil, Editora da UFRJ, Río de Janeiro, 1997, pp. 99-114.
} 
cultural que valoriza la etnografía y los vencidos en la historia. Esta primera fase brasileña en términos de protección del patrimonio histórico (que va de 1930 a 1970) presentaría los siguientes rasgos: a) legitimación de las acciones públicas por decisiones políticas de fuerte impacto histórico y ambiental sin una sólida fundamentación jurídica o técnica; b) apreciación de los bienes a partir de criterios predominantemente estéticos; c) fuerte actuación del Gobierno en la creación de un sistema legal de protección; d) prevalencia de la actuación federal, a pesar de la existencia de órganos públicos regionales; y e) preocupación más intensa por la formación artificial de una identidad nacional que por la cuestión cultural ${ }^{15}$.

A partir de las décadas de 1960 y 1970 sobrevienen la radicalización de la política y la politización de la cultura en Brasil, simultáneamente a un golpe de Estado que instaura una dictadura de derechas en 1968. La intensa censura estatal es acompañada, paradójicamente, por un movimiento de izquierdas que critica el modernismo. Surge, así, el posmodernismo, que introduce cuestiones relativas a la raza, el sexo y la ecología en las disciplinas conectadas con la protección del patrimonio histórico y ambiental. Por otro lado, la actuación del IPHAN entra en decadencia: sufre las consecuencias de la falta de dinero, de la especulación inmobiliaria y de la indiferencia de la población respecto al tema. Más importante que la idea de preservación es la ideología del “desarrollismo”, que da preferencia a la industrialización, a la modernización y a la urbanización ${ }^{16}$.

Para salir de la crisis, la fuente de inspiración fue el modelo europeo, que buscaba equilibrar los intereses histórico-culturales con los intereses económicos y se basaba en la política oficial de la Unesco, consagrada en la Convención de $1972^{17}$. En este contexto, la preocupación por la arqueología industrial y por bienes muebles como máquinas y equipamientos típicos de la memoria industrial no era prioritaria. Sin embargo, la valorización de los conjuntos urbanos como un todo (y no solamente como edificios aislados) acabó por fomentar también la protección en dicho ámbito.

\footnotetext{
${ }^{15}$ Ibidem, pp. 118-138.

${ }^{16}$ FONSECA, O patrimônio... cit., pp. 149-159.

${ }^{17}$ FUNARI, Pedro Paulo y PELEGRINI, Sandra C. A., Patrimônio Histórico e Cultural, Jorge Zahar, Río de Janeiro, 2009, 2. ${ }^{\text {e ed., p. } 25 .}$
} 


\section{CUESTIONES CONCEPTUALES RELATIVAS A LA PROTECCIÓN DEL PATRIMONIO CULTURAL}

La clasificación y la preservación de bienes históricos y culturales importantes para el medio ambiente dependen del significado simbólico que se les asigna ${ }^{18}$. Ya sea en Brasil, en Latinoamérica o en Europa, es habitual que existan perspectivas diferentes. Por mucho tiempo Brasil fue influenciado por tendencias europeas. Sin embargo, en la práctica, hay mucho eclecticismo y se dan situaciones fuera del estándar clásico en las diferentes regiones de Brasil.

Este valor cultural se basa comúnmente en su valor histórico-lusitano, es decir, en la valoración de la tradición cultural recibida originalmente de los portugueses durante el proceso de colonización, o bien está tradicionalmente vinculado a una concepción típicamente republicana de "interés público"19. Es imprescindible reconocer también que el concepto de "identidad" es algo variable, sobre todo cuando se toman en cuenta las diversas herencias coloniales y vínculos cívicos. En general, identidad es algo relativo a "pertenecer", o sea, a un "nosotros" que se diferencia de "los otros". Remite, por lo tanto, a la herencia de los antepasados mediante un vínculo intergeneracional ${ }^{20}$.

En el caso brasileño se buscaba constituir un vínculo nacional artificial a partir del grupo étnico y cultural dominante —el portugués- Inicialmente, la valorización de los bienes recaía básicamente en el concepto de monumento, ya fueran los monumentos entendidos como "intencionales" (los que pretenden perpetuar la memoria de un hecho, persona o pueblo), ya los "históricos" propiamente dichos (que son aquellos cuyo valor excede su intención inicial por su excepcionalidad histórica) $)^{21}$.

Es un hecho aceptado que todo monumento cuenta con una dimensión histórica y una dimensión estética. Pero la noción de valor histórico cada vez se volvió más compleja a raíz del desarrollo de los estudios sobre el tema. Así, hubo una progresiva ampliación de lo que se considera un bien con "valor histórico" en Brasil. Dicha ampliación también se

\footnotetext{
${ }^{18}$ CAMARGO, Patrimônio Histórico... cit., p. 29.

${ }^{19}$ FONSECA, O patrimônio... cit., p. 34.

${ }^{20}$ LORCA, Noemi, "Identidad y patrimônio cultural", Castriota, Leonardo Barci y Souza, Luiz Antônio Cruz (coords.), Anais do 1 Fórum Brasileiro do Patrimônio Cultural, Belo Horizonte, 2004, p. 39.

${ }^{21}$ CAMARGO, Patrimônio Histórico... cit., p. 24.
} 
produjo en diferentes países, lo que refleja la fuerte relativización de este concepto a lo largo de los años.

En la actualidad prevalece la idea de que deben ser considerados ciertos valores "no explicitados", es decir, concepciones que provienen de una percepción más intuitiva y menos erudita respecto de qué es importante o no. En este sentido, parece útil la dicotomía entre el "valor antigüedad" y el "valor novedad", que son conceptos típicos del siglo XX y se alejan del mero "valor histórico", que fue el tradicional hasta el siglo XIX. Por una parte, la "antigüedad" busca mantener intactas las marcas del proceso histórico, al contrario del punto de vista anterior, que admitía la restauración plena de casi todo (como si buscara traer el bien al presente). Por otra, la "novedad" se conecta con el "valor de uso". Y, en este caso, existe también un fuerte interés en reformas puntuales para una adaptación a las exigencias sociales típicas del consumo, puesto que en la segunda mitad del siglo XX surge un nuevo fenómeno: el consumo cultural de masas, que aumenta las expectativas estéticas respecto a los bienes del patrimonio histórico ${ }^{22}$.

Algunos autores afirman que a partir de la década de 1980 se impone en Europa una visión nostálgica respecto al patrimonio histórico. Eso también ocurre en Brasil, aunque de forma más tímida y reciente. La crisis económica afecta a los museos, por lo que estos deben entrar en la industria del ocio y del turismo a fin de aprovechar esa nueva demanda social, es decir, el hecho de que las personas busquen disponer y disfrutar de un pasado perdido por medio de edificios, monumentos, objetos, tótems y los más variados recordatorios. Esos bienes proporcionan un viaje mental que provoca sensaciones agradables a la gente. A partir de esta nueva perspectiva (el consumo de la historia), las intervenciones puntuales modificativas pasan a ser consideradas adecuadas, sobre todo en ambientes urbanos, con lo que lo antiguo se une a lo nuevo de forma innovadora, si bien manteniéndose la memoria cultural ${ }^{23}$.

A principios de la década de 1990 la llamada - en aquel momento- Comunidad Económica Europea se dedicó prioritariamente a la política del turismo. El objetivo era compartir crecimiento económico y defensa del medio ambiente y del patrimonio cultural. Esta necesidad del turismo inicialmente ignoraba (a propósito o no) los efectos

\footnotetext{
${ }^{22}$ FONSECA, O patrimônio... cit., p. 68.

${ }^{23}$ REIS, Antônio Tarcísio y SOUZA, Gabriel Nobre, “O projeto do 'Le Grande Louvre': uma análise estética e de usos”, Arquiteturarevista, vol. 12, núm. 2, pp. 140-153.
} 
nocivos para la comunidad local, como la masificación, la pérdida de identidad, las afectaciones a los bienes, etc. Sin embargo, la búsqueda de un equilibrio entre explotación y conservación pasó paulatinamente a ser una preocupación conjunta de los sectores del turismo y del patrimonio. El Estado social europeo de la segunda mitad del siglo XX buscó integrar la sociedad civil de forma planeada y democrática $-\mathrm{y}$ la preservación del patrimonio cultural ha servido a dicho propósito-, lo que no impidió el surgimiento de nuevos problemas, como los movimientos de masas típicos del consumo exacerbado y la desvalorización de los expertos del ámbito de la preservación. En este sentido, los museólogos, los historiadores y los arqueólogos pierden terreno dentro de los museos frente a los administradores, los gerentes y los relaciones públicas. Así, el conocimiento especializado se ha visto forzado a ceder en función de imperativos económicos y políticos. En este contexto, han prevalecido los criterios de eficiencia empresarial, por lo que el consumo, que antes era algo accesorio, se ha convertido en la prioridad ${ }^{24}$.

La discusión entre el valor antigüedad y el valor histórico corresponde más bien al ámbito técnico-académico. Sin embargo, el debate entre el valor antigüedad y el valor novedad involucra los diferentes sectores de la sociedad y condiciona la formulación de nuevas políticas públicas. Se crean nuevos criterios de clasificación y otros desaparecen, aunque se mantienen algunos estándares; en general, por ejemplo, las edificaciones y los monumentos tienen su valor novedad reforzado; por su parte, las ruinas y los yacimientos arqueológicos importan más por su valor antigüedad. Respecto a los bienes muebles, en general se mantienen intactos, más como viejos que como antiguos. Sin embargo, se exponen en museos en los que se garantiza, en su conjunto, la novedad como valor ${ }^{25}$. Esta última característica es válida también para los parques y los paisajes.

Pero está el reverso de la moneda: si, por una parte, el factor económico pasa a ser relevante en la cuestión de la preservación de los bienes culturales; por otra, surge una fuerte preocupación académica por los olvidados, los “outsiders" de la historia. Esto es fruto del avance de la historiografía de las mentalidades sobre la historiografía factual ${ }^{26}$. Obreros, campesinos, inmigrantes, minorías, etc., pasan a tener su historia contada por

\footnotetext{
${ }^{24}$ BALLART, Josep, El patrimonio histórico y arqueológico: valor y uso, Ariel, Barcelona, 1997, pp. 240247.

${ }^{25}$ FONSECA, O patrimônio... cit., p. 70.

${ }^{26}$ CHARTIER, Roger, A história cultural: entre práticas e representações, Difel, Lisboa, 1990. Traducción de Maria Manuela Galhardo.
} 
medio de una noción ampliada de patrimonio. Sin embargo, hay quien no está de acuerdo con este punto de vista.

Los consagrados autores André Chastel y Jean-Pierre Babelon publicaron un artículo en Francia en 1980 (que luego se editó como libro) que defendía que el valor etnográfico no sería compatible con la idea de patrimonio ${ }^{27}$. El mobiliario de las casas, por ejemplo, no puede ser considerado patrimonio si no contiene nada de grandioso o "sagrado" para la sociedad $^{28}$. Esta concepción, por razones obvias, no era comprendida por los pensadores brasileños de finales del siglo XX. Con razón, Maria Cecília Fonseca critica dicho punto de vista, que sería “ideológico" y "despolitizado" ${ }^{29}$. En museología, buscar la "excepcionalidad" es algo que el pensamiento técnico predominante en Latinoamérica en la transición hacia el siglo XXI considera anacrónico y elitista.

\section{LA PROTECCIÓN JURÍDICA DE LOS BIENES CULTURALES POR MEDIO DEL INSTITUTO URBANÍSTICO DEL TOMBAMENTO}

El tombamento es un acto de intervención en la propiedad que puede ser realizado por ley, si bien en general es llevado a cabo directamente por la Administración pública. O sea, es un acto administrativo — cuyo objetivo es declarar el valor especial de un bien con la finalidad de garantizar su protección para las actuales y futuras generaciones-. Dicho valor especial, de acuerdo con la Constitución Federal brasileña, puede basarse en diferentes fundamentos: puede ser un valor histórico, artístico, paisajístico, arqueológico o arquitectónico, o un valor cultural propiamente dicho ${ }^{30}$. Dentro de este contexto, el tombamento se está convirtiendo en un importante instrumento de protección ambiental ${ }^{31}$. El término tombar, en su acepción jurídica, significa 'registrar o inventariar'. Su origen se remonta a la historia de Portugal. Es un término derivado de la transferencia del

\footnotetext{
${ }^{27}$ BABELON, Jean-Pierre y CHASTEL, André, "La notion de patrimoine", Revue de l'Art, núm. 49, París, 1980, pp. 5-32.

${ }^{28}$ Un buen resumen de las posiciones de los autores puede ser encontrado en: BO, João Batista Lanari, Proteção do patrimônio na UNESCO: ações e significados, Unesco, Brasília, 2003.

${ }^{29}$ FONSECA, O patrimônio... cit., p. 74.

${ }^{30}$ FERNANDES, Edésio y ALFONSIN, Betânia (coords.), Revisitando o instituto do tombamento, Fórum, Belo Horizonte, 2009.

${ }^{31}$ ALVES, Alexandre Ferreira de Assumpção, "O tombamento como instrumento de proteção ambiental”, Revista Brasileira de Estudos Políticos, vol. 98, núm. 2, julio/diciembre 2008.
} 
Archivo Nacional portugués, en 1375, ante el incendio en una de las torres del castillo de San Jorge. La nueva sede elegida fue la Torre do Tombo (cuyo acervo aumentó tras el terremoto de 1755, sobre todo por acción del marqués de Pombal). Llevar documentación a la Torre do Tombo para su registro sería, así, el acto de tombar. Un acto que no impide el ejercicio del dominio por el propietario, si bien restringe el uso del bien. En el caso de los bienes inmuebles, el tombamento es un problema, pues muchas veces reduce las opciones de su utilización y, en consecuencia, el valor económico del bien; en el caso de los bienes muebles, el tombamento produce un efecto inverso, de valorización económica, lo que a menudo los hace objeto de robos $^{32}$.

Actualmente, la Constitución brasileña prevé expresamente la preservación del patrimonio cultural por medio del tombamento de bienes muebles e inmuebles, entre otras medidas, como el registro de bienes inmateriales. Se trata de un instituto jurídico antiguo para los patrones legislativos brasileños. El Decreto-Ley 25, publicado en 1937, regula el tombamento hasta la fecha.

Según el artículo 23, III, de la Constitución brasileña, la competencia para realizar el tombamento es compartida por todas las entidades de la Federación, es decir, la Unión (el poder central), los estados y los municipios pueden tombar bienes culturales. Obviamente, todas las entidades de la Federación poseen interés en preservar el patrimonio. Pero, a fin de atribuir la competencia administrativa para efectuar la protección del patrimonio, la cuestión, según la doctrina brasileña, se rige por el "principio de la predominancia del interés"33. Dicho principio es muy utilizado, aunque en general de forma retórica, debido a su contenido fluido y al hecho de que puede variar según el caso concreto. Es habitual que más de un ente establezca mecanismos de preservación para el mismo caso. Y esto pasa muchas veces de forma descoordinada, lo que genera conflictos e incluso disputas judiciales entre los entes de la Federación.

La emisión de leyes sobre tombamento es una competencia compartida entre la Unión (el poder central) y los estados (conforme al artículo 24, VII, de la Constitución) ${ }^{34}$. Así pues, es competencia del Estado Federal la elaboración de normas generales, mientras que

\footnotetext{
${ }^{32}$ FONSECA, O patrimônio... cit., p. 206.

${ }^{33}$ RODRIGUES, Patrimônio cultural... cit., p. 129.

${ }^{34}$ Artículo 24: “Compete à União, ao Estados e ao Distrito Federal legislar concorrentemente sobre: [...] VII - proteção ao patrimônio histórico, cultural, artístico, turístico e paisagístico”.
} 
corresponde a los estados la aprobación de normas específicas y complementarias. Es interesante observar que el texto constitucional no menciona los municipios; por eso, parte de la jurisprudencia nacional rechaza la competencia legislativa municipal en esta cuestión. La doctrina está dividida, con una marcada divergencia en cuanto a la competencia legislativa de los municipios en materia de tombamento. En cualquier caso, nada impide que los municipios legislen sobre otras formas de protección de su patrimonio histórico y cultural a partir de una interpretación sistemática de la Constitución ${ }^{35}$.

Conforme a la actual legislación brasileña, el tombamento puede incidir sobre bienes muebles e inmuebles, materiales e inmateriales, públicos y privados. Algunos tipos de bienes no pueden ser tombados, como, por ejemplo, las sedes de representaciones diplomáticas o los bienes que pertenezcan a tiendas de anticuarios ${ }^{36}$.

Los criterios para el tombamento (y para la protección de los bienes culturales en general) son la autenticidad y la integridad. La autenticidad se refiere a una conservación sustancialmente inalterada de los aspectos exteriores. Sin embargo, actualmente este no es un criterio exacto, pues depende del contexto sociocultural del bien. La integridad es la evaluación del aspecto físico del bien y su no alteración por medio de la intervención humana ${ }^{37}$.

Los efectos del tombamento son: (i) la "inmodificabilidad" (o sea, el bien no puede ser reformado, modificado o demolido, y su restauración depende de la autorización del poder público); (ii) la limitación de la alienabilidad (o sea, si es público, se torna inalienable al particular); (iii) la más intensa protección del Estado (es decir, el órgano público tiene derecho de acceso directo y vigilancia, sin necesidad de autorización judicial, y el poder público tiene el deber de proteger el bien si el propietario se declara imposibilitado); (iv) la imposibilidad de expropiación forzosa, excepto para mantener el propio tombamento o después de cancelarlo; y, finalmente, (v) las restricciones a inmuebles vecinos (por ejemplo, para garantizar la visibilidad del bien) ${ }^{38}$. Por regla

\footnotetext{
${ }^{35}$ Esta es la posición defendida por la mayoría de la doctrina, como, por ejemplo, Regina Ferrari. FERRARI, Regina Maria Macedo Nery, Direito Municipal, RT, São Paulo, 2005, 2. a ed., p. 296.

${ }^{36}$ NOHARA, Irene Patrícia, Direito Administrativo, Atlas, São Paulo, 2017, 7. a ed., p. 782.

${ }^{37}$ SILVA, As cidades... cit., p. 98.

${ }^{38}$ PIETRO, Maria Sylvia Zanella di, Direito Administrativo, Atlas, São Paulo, 2016, 29. a ed., p. 183.
} 
general, el tombamento es una forma de intervención en la propiedad que no implica indemnización. Solo habrá indemnización a ser pagada por el Estado en el caso de comprobarse un perjuicio efectivo para el propietario.

La doctrina brasileña, en función de diferentes criterios, suele identificar distintos tipos de tombamento. Por ejemplo:

1) Respecto a la iniciativa, el tombamento puede ser: a) de oficio, realizado sobre bienes públicos —en este caso es suficiente la notificación a la entidad a la cual pertenece el bien o al órgano al cual está vinculado-; b) voluntario, realizado sobre bien privado - en este caso puede consistir en la petición previa del propietario o en su aceptación de la notificación realizada por el poder público; y c) obligatorio, realizado sobre bien privado cuando el propietario no acepta la decisión del poder público —en este último caso se inicia un proceso administrativo de tombamento, garantizándose el contradictorio y la amplia defensa-

2) Respecto a la forma de constitución del tombamento, puede ser: a) provisional, tras la notificación al propietario — en este caso se trata solo de una medida de precaución y no de un tombamento propiamente dicho-; y b) definitivo, con la inscripción en el livro de tombo.

3) Respecto a los destinatarios, el tombamento puede ser: a) general, relativo a un grupo indeterminado de bienes y personas, como, por ejemplo, el tombamento de la ciudad de Ouro Preto; y b) especial, relativo a un bien determinado ${ }^{39}$.

El procedimiento relativo al tombamento puede variar según sea un acto de la Unión (el poder central), de los estados o de los municipios. A título ejemplificativo, si el tombamento es federal, el proceso seguirá tres fases: (i) la notificación al propietario, que puede aceptar el tombamento o impugnarlo en quince días - si no hay impugnación, se efectúa el registro en el libro; si la hay, se comunica dicha impugnación a la entidad notificadora-; (ii) el consejo competente decide, en el plazo de sesenta días, si mantiene el tombamento - en cuyo caso la decisión es enviada para su homologación al ministro de Cultura - o no —en cuyo caso el proceso es archivado-; y (iii) homologado el

\footnotetext{
${ }^{39}$ ARAÚJO, Edmir Neto de, Curso de Direito Administrativo, Saraiva, São Paulo, 2014, 6. ${ }^{\text {a } e d ., ~ p . ~} 1188$.
} 
tombamento, cabe aún la posibilidad de recurrir al presidente de la República, que puede cancelarlo (algo que, sin embargo, es muy improbable) $)^{40}$.

A nivel federal, la entidad responsable del tombamento es una autarquia (una entidad estatal descentralizada y dotada de personalidad jurídica propia y de derecho público) denominada Instituto del Patrimonio Histórico y Artístico Nacional (IPHAN). El instituto guarda actualmente cuatro diferentes libros de registro, llamados Livros do Tombo: el arqueológico, etnográfico y paisajístico, el histórico, el de bellas artes y el de artes aplicadas. Hasta la década de 1960 los procesos eran rápidos y sucintos. Gradualmente los procesos se fueron complicando y dieron lugar a extensos dosieres consistentes en: petición de tombamento, notificación al propietario, informes técnicos, actas de reuniones, impugnaciones, recursos, recortes de periódico, manifestaciones suscritas, folletos y proyectos, entre otros documentos ${ }^{41}$.

Otro detalle interesante es que un mismo bien puede ser tombado por diferentes entes políticos y estar inscrito en más de un libro. Asimismo, los bienes inmuebles deben tener el tombamento transcrito en la oficina de registro de inmuebles. Finalmente, aunque en un principio el término tombamento era utilizado para bienes materiales e inmateriales, hoy día solo se usa para los materiales. Técnicamente, los bienes inmateriales son registrados, no tombados ${ }^{42}$. El registro guarda actualmente cuatro diferentes libros: saberes, celebraciones, formas de expresión y lugares.

En caso de que el tombamento se demuestre insuficiente para la protección del bien, el poder público puede adoptar otras medidas: a) proceder a su expropiación forzosa, es decir, retirar totalmente la propiedad mediante previa y justa indemnización al propietario; b) establecer una protección genérica dentro de las llamadas leyes de zonificación municipal; y c), en caso de incumplimiento del tombamento, imponer las sanciones de carácter criminal en los términos previstos en la Ley 9.605/98. El artículo 62 de dicha ley prevé como crimen la destrucción o inutilización del bien protegido, con pena de uno a tres años de reclusión y multa. El artículo 63 establece la misma pena para la alteración de una edificación protegida.

\footnotetext{
${ }^{40}$ CARVALHO, Raquel Melo Urbano de, Curso de Direito Administrativo, Juspodium, Salvador, 2009, 2. ${ }^{\mathrm{a}}$ ed., p. 1053.

${ }^{41}$ FONSECA, O patrimônio... cit., p. 208.

42 NOHARA, Direito Administrativo... cit., p. 777.
} 
Además, existe la previsión de dos procedimientos judiciales muy importantes para la protección del patrimonio público en el sistema jurídico brasileño. La Ley de Acción Civil Pública (Ley 7.347/85) confiere legitimidad para proponer el pleito al Ministerio Público (Fiscalía), a la Defensoría Pública, a la Unión (el poder central), a los estados, a los municipios, a las otras entidades estatales y, también, a las asociaciones constituidas desde hace más de un año que tengan la protección del patrimonio como uno de sus objetivos. La Ley de Acción Popular (Ley 4.717/65), por su parte, atribuye a cualquier ciudadano el derecho de proponer un juicio para evitar cualquier forma de intervención ilícita en el patrimonio cultural —especialmente en relación con el medio ambiente urbano-.

En términos prácticos, hay ejemplos interesantes de importantes iniciativas de protección mediante sistemas -desarrollados en diferentes centros de investigación y documentación brasileños- que crean bases de datos de los bienes protegidos. Una de las iniciativas más importantes es la Base de Datos del Inventario Nacional de Bienes Inmuebles de Sitios Urbanos Tombados de Ouro Preto y Mariana, creada por la Escuela de Arquitectura de la Universidad Federal de Minas Gerais. Este proyecto fue financiado con recursos del Programa Monumenta, que es un convenio entre la Unesco, el Banco Interamericano de Desarrollo y el Ministerio de la Cultura de Brasil ${ }^{43}$. Otro ejemplo interesante es el Proyecto de Digitalización y Gestión de Bienes Muebles del Centro de Conservación y Restauración de Bienes Culturales Muebles (CECOR), órgano de la Escuela de Bellas Artes de la Universidad Federal de Minas Gerais ${ }^{44}$.

\section{LA DEBILIDAD RESPECTO A LA PROTECCIÓN DEL PATRIMONIO MINERO EN BRASIL}

El patrimonio cultural también incluye el patrimonio geológico, que, a su vez, está constituido por geositios, afloramientos de rocas, minerales o fósiles, conjuntos

\footnotetext{
${ }^{43}$ FREITAS, Vanessa Regina, "Inventário de Ouro Preto e Mariana: instrumento de proteção", Castriota, Leonardo Barci y Souza, Luiz Antônio Cruz (coords.), Anais do 1 Fórum Brasileiro do Patrimônio Cultural, Belo Horizonte, 2004, p. 37.

${ }^{44}$ NUNES, Flávio Humberto Cabral y ARAÚJO, Arnaldo de Albuquerque, "Digitalização e gerenciamento do acervo sobre conservação e restauração de bens culturais móveis do CECOR", Castriota, Leonardo Barci y Souza, Luiz Antônio Cruz (coords.), Anais do 1 Fórum Brasileiro do Patrimônio Cultural, Belo Horizonte, 2004, p. 43.
} 
paisajísticos y colecciones de geociencias o historia natural. Cuando uno de esos conjuntos se encuentra relacionado con actividades de extracción, puede considerarse "patrimonio minero". Asimismo, estos tipos de bienes pueden clasificarse como de carácter geomorfológico, paleontológico, espeleológico, paleoambiental o tectónico. En Brasil, son ejemplos interesantes de patrimonio minero la Mina Brejuí, en el estado de Rio Grande do Norte, y el Itinerario del Turismo Mineral del Nordeste, que va del estado de Ceará al estado de Rio Grande do Norte ${ }^{45}$.

En general, la tradición brasileña responde a una concepción de patrimonio basada predominantemente en atributos estéticos y en una visión elitista de la historia ${ }^{46}$. Eso conlleva que la cuestión de la protección del patrimonio cultural ligado a la minería (no solo los bienes inmuebles, como los relativos al medio ambiente, sino también los bienes muebles, como equipamientos y máquinas) no sea considerada prioritaria.

En el siglo XVIII se descubrieron importantes yacimientos de oro en la provincia que más tarde pasó a ser llamada Minas Gerais, aunque no solo allí. En São Paulo, después del oro, se encontraron yacimientos de plomo y plata, particularmente en la región del Vale do Ribeira, que fueron explotados durante cerca de tres siglos hasta principios de la década de 1990, cuando las minas fueron cerradas ${ }^{47}$.

En Brasil, como en otras partes del mundo, la idea de un "patrimonio minero" está vinculada a la protección de los espacios geológicos explotados, pero también a la “arqueología industrial”. En Inglaterra, el desarrollo de la arqueología industrial ha propiciado fuentes importantes para estudios científicos realizados en otras áreas, como

\footnotetext{
${ }^{45}$ NASCIMENTO, Marcos Antonio Leite do, ROCHA, Antonio José Dourado y NOLASCO, Marjorie Cseko, "Patrimônio geológico e mineiro no nordeste do Brasil", Boletim Paranaense de Geociências, vol. 70, 2013, pp. 104 a 113.

${ }^{46}$ ROSA, Carolina Lucena, "O patrimônio industrial: a construção de uma nova tipologia de patrimônio", Anais do XXVI Simpósio Nacional de História - ANPUH, São Paulo, julio de 2011, p. 12. Recuperado el 8 de enero de 2018 de <http://www.snh2011.anpuh.org/resources/anais/14/1308189074_ARQUIVO_artigoANPUHCarolinaRos a.pdf.>.

${ }^{47}$ SÁNCHEZ, Luis Enrique, "Patrimônio mineiro do Vale do Ribeira", Jornada Iberoamericana sobre el patrimonio geológico-minero, Santa Cruz de La Sierra, Bolívia, 2002. Recuperado el 8 de enero de 2018 de

<http://w3.cetem.gov.br/cytedxiii/Downloads/Coloq_pat_geo_min_Bolivia/Patrimonio\%20en\%20Casos $\% 20$ Especificos/Luis\%20Enrique\%20S\%C3\%A1nchez_PonenciayFotos/LuisEnriqueSanchez_Patrimoni oValedoRibeira.doc.>.
} 
la historia social, la economía o la sociología. La idea es superar la historia factual realizando una historia que valore de forma más contundente las experiencias humanas ${ }^{48}$. En cuanto a la protección del patrimonio industrial vinculado a la minería, es sabido que Francia editó la primera norma que recogía el inventario de máquinas, planos y documentos con valor histórico. Así, en 1791 se creó el famoso Conservatoire des Arts et Métiers (Conservatorio de Artes y Oficios), primer museo técnico del mundo. También Reino Unido, Francia, Alemania, España, Austria, Bélgica y, más recientemente, Italia y Portugal cuentan con una amplia experiencia en este ámbito ${ }^{49}$.

Desafortunadamente, este no es el caso de Brasil. La arqueología industrial exige un conocimiento metalúrgico propio, un conocimiento que sirva para comprender la memoria cultural y ambiental. En Brasil todavía son escasos los textos científicos sobre arqueología industrial $^{50}$ y casi inexistentes las investigaciones sobre el patrimonio minero.

Los estudios y las investigaciones realizados por los brasileños todavía son muy incipientes, al contrario de lo que sucede en países como México o Chile, donde ya existe una tradición académica en la materia. Y quizá eso sea natural si se tiene en cuenta que el proceso brasileño de industrialización se inició en la década de 1930. El primer artículo académico sobre arqueología industrial publicado en Brasil es de 1976 y se titula "Fábrica de São Luiz de Itu: um estudo de arqueologia industrial”, escrito por Warren Dean, un historiador estadunidense. Solo en 2004 se constituyó la representación brasileña del The International Committee for the Conservation of the Industrial Heritage (TICCIH). A diferencia de otros países, la representación brasileña no dispone de un sitio internet, aunque sí de un perfil en Facebook (TICCIH-Brasil) ${ }^{51}$.

En Brasil existen casos aislados de protección del patrimonio industrial (entendido en sentido amplio). Sin embargo, cabe destacar algunos buenos ejemplos de dicha protección, como el registro del Oficio de las Paneleiras de Goiabeiras (en el estado de

\footnotetext{
${ }^{48}$ SILVA, Ronaldo A. Rodrigues, "Arqueologia industrial e patrimônio industrial: 'novo' enfoque à memória cultural", Fórum Patrimônio, vol. 2, 2002. Recuperado el 8 de enero de 2018 de <http://www. forumpatrimonio.com.br/seer/index.php/forum_patrimonio/article/download/53/48.>.

${ }^{49}$ MARTÍNEZ, L. F. Mazadiego y RIART, O. Puche, La conservación del patrimonio minero metalúrgico europeo: inventario, actuaciones de conservación, archivos y museos. Recuperado el 9 de enero de 2018 de <http://oa.upm.es/9893/1/igme_109-1.pdf.>.

${ }^{50}$ SILVA, “Arqueologia industrial..." cit.

${ }^{51}$ ROSA, O patrimônio... cit., pp. 1-11.
} 
Espírito Santo) o el tombamento de las restos de la Real Fábrica de Hierro São João do Ipanema (en la ciudad de Iperó, en el estado de São Paulo) ${ }^{52}$.

Específicamente en el caso del patrimonio industrial minero, cabe mencionar algunos ejemplos. En primer lugar, el Museo Virtual Geo-diversidad en la Educación, de la Universidad Estatal de Ponta Grossa, en el estado de Paraná; se trata de un museo interesante que se centra fundamentalmente en el ámbito geológico-ambiental, no en el arqueológico $^{53}$.

Otro ejemplo destacado es el Museo de Mineralogía Professor Djalma Guimarães, creado en homenaje a uno de los pioneros de la geociencia en Brasil; se encuentra en la ciudad de Belo Horizonte, en Minas Gerais, y su colección está constituida por más de tres mil muestras de minerales, rocas, fósiles y meteoritos (en su mayor parte procedentes del propio estado). Este museo, como el anterior, no tenía como objetivo exactamente la conservación del registro arqueológico del patrimonio relacionado con la industria de la minería, sino del geológico-ambiental, que actualmente se encuentra incluido en el Museo de las Minas y del Metal. Dicho museo está ubicado en un importante edificio — desde el punto de vista estético e histórico- de 1897 que fue restaurado en 2009. Alberga una importante colección de minerales, y también se centra en la actividad de minería y metalurgia. Se trata de un museo tecnológicamente avanzado y con diversos recursos interactivos para los visitantes ${ }^{54}$.

Asimismo, cabe destacar el Museo de Artes y Oficios (también en Belo Horizonte), que es patrimonio público desde 2005. El museo cuenta con una colección compuesta por piezas originales de los siglos XVIII a XX relativas a trece oficios diferentes, entre los cuales uno de los más destacados es la minería ${ }^{55}$.

Y, finalmente, el cuarto ejemplo es el Museo Estatal del Carbón, que quizá sea el más importante del país en ese ámbito. Fue creado en 1986 y se halla en la ciudad de Arroio dos Ratos, en el estado de Rio Grande do Sul. Está situado en las ruinas de la primera

\footnotetext{
52 SILVA, “Arqueologia industrial..." cit.

${ }^{53}$ Universidad Estatal de Ponta Grossa, Geodiversidade na Educação - Museu Virtual. Recuperado el 9 de enero de $2018 \mathrm{de}<\mathrm{http} / /$ www.geocultura.net/museu-virtual/>.

54 MMM Gerdau - Museu de Minas e do Metal. Recuperado el 9 de enero de 2018 de <http://www.mmgerdau.org.br/>.

55 Museu de Artes e Ofícios. Recuperado el 9 de enero de 2018 de <http://www.mao.org.br/conheca/historia-da-colecao/>.
} 
usina termoeléctrica de Brasil, que necesitaba carbón mineral para su funcionamiento. El museo exhibe una pequeña colección de bienes muebles (es decir, casi no cuenta con equipamientos y máquinas). Su patrimonio principal está compuesto por tres tipos de bienes: las edificaciones, la colección geológica y la colección documental. Particularmente importante fue la creación por parte del museo del Archivo Histórico de la Minería, cuya metodología se inspiró en el Grupo de Archivistas Municipales de Madrid. Dicho método de investigación utiliza un sistema, llamado "diplomática", “diplomática contemporánea" o "diplomática archivística", que no tiene como preocupación principal el conocimiento sobre la institución responsable de producir los documentos, sino los procedimientos administrativos que llevaron a la producción de los archivos. En este sentido, se estudia fundamentalmente la parte interna de los documentos, sobre todo su parte jurídica. Dicho método es considerado por algunos investigadores como el más adecuado para el registro de información respecto al patrimonio histórico mineral. Además, el museo es hoy día un importante centro de grandes eventos, de forma que posee una función económica separada de su función en el ámbito de la protección del patrimonio mineral ${ }^{56}$.

El Museo del Carbón es el resultado del tombamento realizado a nivel estatal de un importante conjunto patrimonial. La legislación estableció cinco diferentes zonas de protección en torno al área minera: 1) zona de protección rigurosa, 2) zona de protección secundaria e intervención rigurosa, 3) zona de protección secundaria e intervención $a$ posteriori, 4) zona de protección ambiental rigurosa y 5) zona de protección ambiental secundaria. Parte de los bienes relacionados con la actividad minera fueron restaurados minuciosamente. Otra parte se dejó en su aspecto original envejecido. Es decir, se mantuvo deliberadamente visible la acción del tiempo en parte de la colección. Igualmente, el museo desarrolla actividades de promoción e interacción con la comunidad local (escuelas, órganos públicos, etc.) ${ }^{57}$.

\footnotetext{
${ }^{56}$ CARDOSO, Jéssica Fernanda Cherer, A definição de tipologias documentais para o acervo da mineração. Trabalho de Conclusão de Curso. Grado en Biblioteconomía y Comunicación, Universidad Federal de Rio Grande do Sul, 2014, 87 f., p. 38.

${ }^{57}$ GOLASZ, Luiz Henrique Sutelo, Arroio dos ratos, a mineração e o museu do carvão: a história e sua representatividade através da materialidade. Trabalho de Conclusão de Curso. Grado en Historia, Universidad Federal de Rio Grande do Sul. 2013, 81 f., pp. 62-66.
} 
Dichos museos son ejemplos interesantes de eficiencia regulatoria en el ejercicio del poder estatal de intervención en la propiedad pública y en la propiedad privada con el fin de preservar de forma sostenible los bienes vinculados a la memoria cultural. Aparte de ese propósito primordial, según Josep Ballart, también son factores de éxito en la estructuración de museos de minería: 1) la búsqueda de profundización de las diferentes temáticas del museo (aunque su principal atractivo sea la visita turística a su parte geológica); 2) la originalidad en la presentación, considerando que existe una fuerte competencia por parte de otros atractivos turísticos en el país (aunque en Brasil hay pocos museos con dichas características, lo que impide una competencia relevante); 3) la búsqueda de la exclusividad regional; 4) la combinación del uso cultural y del uso comercial; y 5) la integración del museo en circuitos más complejos ${ }^{58}$. La regulación jurídica adecuada de la materia exige, por lo tanto, conocimientos técnicos en otras áreas como la geología, la historia, el urbanismo, la biblioteconomía, la museología, la ecología, el turismo y la economía ${ }^{59}$.

\section{CONCLUSIONES}

La Constitución brasileña garantiza la protección del patrimonio relativo a la identidad y la memoria de la sociedad a partir de un modelo de intervención pública que es típico del Estado social. Existe un amplio conjunto de normas jurídicas en el texto constitucional, en la legislación y en actos administrativos concretos que especifican los deberes de los entes públicos en este ámbito. Sin embargo, la protección del patrimonio histórico, cultural, urbanístico y artístico no es solo responsabilidad de los poderes públicos, sino también, de forma compartida, de la sociedad en general —en este sentido, destaca la necesaria actuación de las universidades y de las entidades técnicas, como los museos-

El tombamento es uno de los instrumentos más importantes de intervención estatal para la protección de este conjunto patrimonial relevante para el interés público. Curiosamente, la palabra tombar es específica del idioma portugués y, dado su peculiar

\footnotetext{
${ }^{58}$ BALLART, El patrimonio histórico... cit., p. 243.

${ }^{59}$ MARTINEZ, L. F. Mazadiego; RIART, O. Puche. La conservación del patrimônio minero metalurgico europeo: inventario, actuaciones de conservación, archivos y museos. Disponível em: <http://oa.upm.es/9893/1/igme_109-1.pdf.> Acesso em 09 jan. 2018.
} 
origen histórico, es intraducible a otros idiomas. Actualmente, sin embargo, el tombamento de bienes inmateriales suele ser denominado también registro.

La protección de bienes culturales en Brasil se inicia tímidamente a partir de la instauración del régimen republicano tras el período monárquico. Inicialmente, solo existían mecanismos de protección de bienes históricos en sentido estricto. Con el paso del tiempo se produjo una evolución paulatina de los institutos jurídicos de intervención en la propiedad. En el siglo XX, principalmente debido a una fuerte influencia europea, el poder público pasa a preocuparse cada vez más por la materia, así como el ámbito académico dirige sus esfuerzos a solucionar los problemas técnicos inherentes a la protección del patrimonio histórico-cultural. Pero el desarrollo de un sistema más sofisticado de protección material solo se inicia con la Constitución de 1988, que recoge tanto influencias externas como presupuestos culturales y jurídicos propios de la realidad nacional.

En general, cuando se compara con los países europeos y algunos latinoamericanos, Brasil lleva años de retraso en el ámbito de la protección del patrimonio histórico-cultural, principalmente en relación con los bienes urbanos y los mineros. Sin embargo, hay importantes iniciativas recientes de preservación en este ámbito, destacando las provenientes de la sociedad civil.

A pesar de los buenos resultados de los casos concretos citados y de las conclusiones jurídicas descritas, todavía no existen investigaciones significativas publicadas en libros y revistas científicos que presenten una comparación práctica entre los factores de éxito y la performance concreta del sistema de regulación jurídica de protección del patrimonio histórico urbano y minero en Brasil.

\section{REFERENCIAS}

ALVES, Alexandre Ferreira de Assumpção, "O tombamento como instrumento de proteção ambiental”, Revista Brasileira de Estudos Políticos, vol. 98, núm. 2, julio/diciembre 2008, Belo Horizonte.

AMARAL, Aracy, “O modernismo brasileiro e o contexto cultural dos anos 20”, Revista USP, núm. 94, junio/agosto 2012, São Paulo, pp. 9-18. 
ARAÚJO, Edmir Neto de, Curso de Direito Administrativo, Saraiva, São Paulo, 2014, 6. ed.

BABELON, Jean-Pierre y CHASTEL, André, "La notion de patrimoine", Revue de l'Art, núm. 49, París, 1980.

BALLART, Josep, El patrimonio histórico y arqueológico: valor y uso, Ariel, Barcelona, 1997.

BO, João Batista Lanari, Proteção do patrimônio na UNESCO: ações e significados, Unesco, Brasília, 2003.

CAMARGO, Haroldo Leitão, Patrimônio Histórico e Cultural, Aleph, São Paulo, 2002.

CARDOSO, Jéssica, Fernanda Cherer, A definição de tipologias documentais para o acervo da mineração. Trabalho de Conclusão de Curso. Grado en Biblioteconomía y Comunicación, Universidad Federal de Rio Grande do Sul. 2014, 87 f.

CARVALHO, Raquel Melo Urbano de, Curso de Direito Administrativo, Juspodium, Salvador, 2009, 2. ${ }^{\mathrm{a}}$ ed.

CHARTIER, Roger, A história cultural: entre práticas e representações. Traducción de Maria Manuela Galhardo. Difel, Lisboa, 1990.

FERNANDES, Edésio y ALFONSIN, Betânia (coords.), Revisitando o instituto do tombamento, Fórum, Belo Horizonte, 2009.

FERRARI, Regina Maria Macedo Nery, Direito Municipal, RT, São Paulo, 2005, 2. ed. FONSECA, Maria Cecília Londres, O patrimônio em processo: trajetória da política federal de preservação no Brasil, Editora da UFRJ, Río de Janeiro, 1997.

FREITAS, Vanessa Regina, "Inventário de Ouro Preto e Mariana: instrumento de proteção", Castriota, Leonardo Barci y Souza, Luiz Antônio Cruz (coords.), Anais do 1 Fórum Brasileiro do Patrimônio Cultural, Belo Horizonte, 2004.

FUNARI, Pedro Paulo y PELEGRINI, Sandra C. A., Patrimônio Histórico e Cultural, Jorge Zahar, Río de Janeiro, 2009, 2. ${ }^{\text {a }}$ ed.

GOLASZ, Luiz Henrique Sutelo, Arroio dos ratos, a mineração e o museu do carvão: a história e sua representatividade através da materialidade. Trabalho de Conclusão de Curso. Grado en Historia, Universidad Federal de Rio Grande do Sul. 2013, 81 f. 
IPHAN - Instituto de Patrimonio Histórico y Artístico Nacional. Revistas e Boletins. $\begin{array}{lllllll}\text { Recuperado el } & 9 & \text { de } & \text { enero } & \text { de } & 2018 & \text { de }\end{array}$ $<$ http://docvirt.com/docreader.net/DocReader.aspx?bib=G:ITrbs_NIRevIPHANIRevIPH AN.docpro>.

LEITE, Letícia Rosa de Almeida, "Patrimônio histórico no México (1914-1939): como surgem as leis e se selecionam memorias", XXVIII Simpósio Nacional de História, Florianópolis, 2015.

LORCA, Noemi, "Identidad y patrimônio cultural”, Castriota, Leonardo Barci y Souza, Luiz Antônio Cruz (coords.), Anais do 1 Fórum Brasileiro do Patrimônio Cultural, Belo Horizonte, 2004.

MARTÍNEZ, L. F. Mazadiego y RIART, O. Puche, La conservación del patrimônio minero metalurgico europeo: inventario, actuaciones de conservación, archivos y museos. Recuperado el 9 de enero de 2018 de <http://oa.upm.es/9893/1/igme_1091.pdf.>.

MMM Gerdau - Museu das Minas e do Metal. Recuperado el 9 de enero de 2018 de $<$ http://www.mmgerdau.org.br/>.

Museo de Artes y Ofícios. Recuperado el 9 de enero de 2018 de $<$ http://www.mao.org.br/conheca/historia-da-colecao/>.

NASCIMENTO, Marcos Antonio Leite do, ROCHA, Antonio José Dourado y NOLASCO, Marjorie Cseko, "Patrimônio geológico e mineiro no nordeste do Brasil", Boletim Paranaense de Geociências, vol. 70, 2013, pp. 104 a 113.

NOHARA, Irene Patrícia, Direito Administrativo, Atlas, São Paulo, 2017, 7. a ed.

NUNES, Flávio Humberto Cabral y ARAÚJO, Arnaldo de Albuquerque, "Digitalização e gerenciamento do acervo sobre conservação e restauração de bens culturais móveis do CECOR", Castriota, Leonardo Barci y Souza, Luiz Antônio Cruz (coords.), Anais do 1 Fórum Brasileiro do Patrimônio Cultural, Belo Horizonte, 2004.

PELEGRINI, Sandra C., Patrimônio cultural: consciência e preservação, Brasiliense, São Paulo, 2009. 
PIETRO, Maria Sylvia Zanella di, Direito Administrativo, Atlas, São Paulo, 2016, 29. ${ }^{a}$ ed.

REIS, Antônio Tarcísio y SOUZA, Gabriel Nobre, “O projeto do 'Le Grande Louvre': uma análise estética e de usos”, Arquiteturarevista, vol. 12, núm. 2, pp. 140-153.

RODRIGUES, Francisco Luciano Lima, Patrimônio cultural: a propriedade dos bens culturais no Estado Democrático de Direito, Universidad de Fortaleza, Fortaleza, 2008.

ROSA, Carolina Lucena, "O patrimônio industrial: a construção de uma nova tipologia de patrimonio", Anais do XXVI Simpósio Nacional de História - ANPUH, São Paulo, julio de 2011. Recuperado el 8 de enero de 2018 de <http://www.snh2011.anpuh.org/resources/anais/14/1308189074_ARQUIVO_artigoAN PUHCarolinaRosa.pdf.>.

SÁNCHEZ, Luis Enrique, "Patrimônio mineiro do Vale do Ribeira", Jornada Iberoamericana sobre al património geológico-minero, Santa Cruz de La Sierra, Bolívia, 2002. Recuperado el 8 de enero de 2018 de <http://w3.cetem.gov.br/cytedxiii/Downloads/Coloq_pat_geo_min_Bolivia/Patrimonio \%20en\%20Casos\%20Especificos/Luis\%20Enrique\%20S\%C3\%A1nchez_PonenciayFot os/LuisEnriqueSanchez_PatrimonioValedoRibeira.doc.>.

SCHIRM, Letícia Dias, "Tombamento: multidisciplinaridade na preservação do patrimônio cultural", Simpósio Nacional de História, 2007, São Leopoldo, RS, Anais do XXIV Simpósio Nacional de História - História e multidisciplinaridade: territórios e deslocamento, Unisinos, São Leopoldo, 2007. CD-ROM.

SILVA, Fernando Fernandes da, As cidades brasileiras e o patrimônio cultural da humanidade, Editora da USP, São Paulo, 2012, 2. ${ }^{\text {e ed. }}$

SILVA, Ronaldo A. Rodrigues, “Arqueologia industrial e patrimônio industrial: 'novo' enfoque à memória cultural", Fórum Patrimônio, vol. 2, 2002. Recuperado el 8 de enero de 2018 de $<$ http://www.forumpatrimonio.com.br/seer/index.php/forum_patrimonio/article/downlo $\mathrm{ad} / 53 / 48 .>$.

SOUZA, Luciana Christina Cruz y MORAES, Nilson Alves, "Estado e patrimônio: o IEPHA/MG e o caso de Minas Gerais”, IV Seminário Internacional-Políticas Culturais, 
Fundação Casa Rui Barbosa, Río de Janeiro, octubre de 2013. Recuperado el 8 de enero de 2018 de

<http://culturadigital.br/politicaculturalcasaderuibarbosa/files/2013/11/LucianaChristina-Cruz-e-Souza-et-alii.pdf.>.

Universidad Estatal de Ponta Grossa, Geodiversidade na Educação - Museu Virtual. Recuperado el 9 de enero de 2018 de <http://www.geocultura.net/museu-virtual/>. 